\title{
Hearing Loss Is Associated With Decreased Nonverbal Intelligence in Rural Nepal
}

\author{
$* \dagger$ Susan D. Emmett, $\$$ Jane Schmitz, §Joseph Pillion, †Lee Wu, \\ $\|$ Subarna K. Khatry, ๆSureshwar L. Karna, †\| Steven C. LeClerq, \\ and $+\|$ Keith P. West Jr.
}

\begin{abstract}
*Department of Otolaryngology-Head and Neck Surgery, Johns Hopkins University School of Medicine; and †Center for Human Nutrition, Department of International Health, Johns Hopkins Bloomberg School of Public Health, Baltimore, Maryland; \$Department of Urban and Environmental Policy, Occidental College, Los Angeles, California; §Department of Audiology, Kennedy Krieger Institute, Department of Physical Medicine and Rehabilitation, Johns Hopkins University School of Medicine, Baltimore, Maryland, U.S.A.; /Nepal Nutrition Intervention Project-Sarlahi; and ISpeech and Hearing Unit, Ganesh Man Singh Memorial ENT Centre, Tribhuvan University Institute of Medicine, Kathmandu, Nepal
\end{abstract}

Objective: To evaluate the association between adolescent and young-adult hearing loss and nonverbal intelligence in rural Nepal. Study design: Cross-sectional assessment of hearing loss among a population cohort of adolescents and young adults.

Setting: Sarlahi District, southern Nepal.

Patients: Seven hundred sixty-four individuals aged 14 to 23 years. Intervention: Evaluation of hearing loss, defined by World Health Organization criteria of pure-tone average greater than 25 decibels $(0.5,1,2,4 \mathrm{kHz})$, unilaterally and bilaterally.

Main outcome measure: Nonverbal intelligence, as measured by the Test of Nonverbal Intelligence, 3rd Edition standardized score (mean, 100; standard deviation, 15).

Results: Nonverbal intelligence scores differed between participants with normal hearing and those with bilateral $(p=0.04)$ but not unilateral $(p=0.74)$ hearing loss. Demographic and socioeconomic factors including male sex; higher caste; literacy; education level; occupation reported as student; and ownership of a bicycle, watch, and latrine were strongly associated with higher nonverbal intelligence scores (all $p<0.001$ ). Subjects with bilateral hearing loss scored an average of 3.16 points lower $(95 \%$ confidence interval, -5.56 to $-0.75 ; p=0.01)$ than subjects with normal hearing after controlling for socioeconomic factors. There was no difference in nonverbal intelligence score based on unilateral hearing loss $(0.97 ; 95 \%$ confidence interval, -1.67 to $3.61 ; p=0.47$ ).

Conclusion: Nonverbal intelligence is adversely affected by bilateral hearing loss even at mild hearing loss levels. Socio economic well-being appears compromised in individuals with lower nonverbal intelligence test scores. Key Words: Cognition-Hearing loss-Nepal-Nonverbal intelligence.

Otol Neurotol 36:86-92, 2015.

\footnotetext{
Address correspondence and reprint requests to Susan D. Emmett, M.D., Center for Human Nutrition, Department of International Health, Johns Hopkins Bloomberg School of Public Health, 615 North Wolfe St., Room E2519, Baltimore, MD 21205, U.S.A.; E-mail: semmett2@jhmi.edu

This study was supported by the Bill and Melinda Gates Foundation (grant OPPGH 614, Global Control of Micronutrient Deficiency), Seattle, WA, U.S.A., the National Institutes of Health (grant 5T32DC000027-25), Bethesda, MD, U.S.A., and the Sight and Life Global Nutrition Research Institute, Baltimore, MD, U.S.A. The original vitamin A supplementation field trial in 1989 to 1991 was supported by Cooperative Agreement No. DAN 0045-A-5094 between the Office of Nutrition, U.S. Agency for International Development, Washington, and the Johns Hopkins University. This work was presented at the International Federation of Otorhinolaryngological Societies 20th World Congress, Seoul, Korea, June 1 to 5, 2013, and the World Health Organization Symposium on Primary Ear and Hearing Care, Seoul, Korea, June 4, 2013.
}

The World Health Organization (WHO) estimates that there are 360 million people worldwide living with hearing loss, a disability known to have profound economic consequences (1). Data from Australia, Sweden, Finland, and the United States consistently demonstrate that adults with hearing loss are more likely to be unemployed or underemployed, and their income may be up to $45 \%$ less than that of the general population (2-7). As a result, many individuals with hearing loss are found in lower-income groups around the world (6). Notably, the global burden of hearing loss is unequally distributed, with $80 \%$ of affected individuals living in low- and middle-income countries (1). Understanding the impact of hearing loss in the developing world, especially the pathways that may be contributing to adverse economic 
consequences, is therefore an essential public health priority.

Two potential pathways that may mediate the relationship between hearing loss and economic outcomes are education and intelligence. Education is a wellestablished contributor to income and employment (8). Multiple studies have demonstrated that hearing-impaired children are at risk for decreased school performance, including grade failure (9), placement in the lowestachieving classes (10), prolonged requirement for an individualized education plan (11), and increased risk of not qualifying for intermediate or higher education (2).

In addition to education, intelligence is also correlated with income and chances of employment (8). Although there is no single definition of intelligence, psychologists have used a battery of intelligence tests for many years to clarify and organize the complex differences in how individuals vary in their ability to reason, understand complex ideas, and react to their environment (12). Similar to the association with poor school performance, children with even mild hearing loss tend to score lower on intelligence tests than their normal-hearing peers $(13,14)$. Given the well-characterized risk of speech and language delay after childhood hearing loss, it is important to delineate between verbal ability and nonverbal intellect. Only a few studies have evaluated nonverbal intelligence in children with hearing loss, each in high-resource settings that focused on severe to profound losses and/or effects among cochlear implant recipients (15-19). To our knowledge, the impact of hearing loss on nonverbal intelligence has not been evaluated in a low-resource rural population typical of high-risk settings where the hearing loss burden is substantial.

We have therefore assessed the relationship between hearing loss and nonverbal intelligence in a cohort of adolescents and young adults in Sarlahi District of rural southern Nepal. The southern plains of Nepal support a populationdense agrarian society that typifies life in the rural Gangetic floodplains of South Asia. The combined prevalence of unilateral and bilateral hearing loss is approximately $6 \%$ to $8 \%$ in adolescents in Nepal, the majority conductive or mixed in origin $(20,21)$. Primary ear and hearing care, including early detection, amplification, surgery, and speech therapy, is not yet available in Sarlahi District or most rural areas of the country. Because more than $80 \%$ of births occur at home, newborn hearing screening is also not routinely done. Defining the public health burden and potential disabilities associated with hearing loss represents a critical step toward establishing a basis for improved care. In this study, we hypothesized that hearing loss would result in measurable decreases in nonverbal intelligence, which may explain, in part, the economic impact of hearing loss and support the need to identify and treat mild to moderate hearing loss early in life.

\section{MATERIALS AND METHODS}

We performed nonverbal intelligence testing on a subcohort of adolescents and young adults aged 14 to 23 years living in Sarlahi District in rural southern Nepal. This subcohort had participated as preschoolers in a placebo-controlled vitamin A supplementation trial in 1989 to 1991 (22) and were followed in an ear health and hearing survey from 2006 to 2008 (23).

\section{Original Trial}

Details of the original randomized trial have been previously described (22). Briefly, 261 administrative wards in 29 contiguous village development communities in Sarlahi District were randomized for resident preschool-aged children to receive vitamin A supplement (200,000 IU) or a placebo capsule during home visits every 4 months. Forty $(15 \%)$ of 261 wards were randomly selected for enrolled children to receive additional nutritional, ophthalmologic, ear, and health assessments $(24,25)$. The ear health and hearing survey was conducted in these 40 wards in 2006 to 2008 .

\section{Ear Health and Hearing Follow-Up Survey}

A list was maintained in the Nepal Nutrition Intervention Project-Sarlahi data center of all participants of the original trial known to have survived to the end of data collection in 1992. The original trial staff, who had remained continuously employed by the project, used this information to make home visits to confirm the identity, residency, and vital status of trial participants and to obtain informed consent (aged $\geq 18 \mathrm{yr}$ or married) or assent with parental consent (aged $<18 \mathrm{yr}$ ) for the 2006 to 2008 survey.

Assessment of ear health and hearing was conducted at a central site in each of the 40 wards as described (21). Audiometric testing was performed using a digital audiometer (240 digital audiometer; Amplivox, Oxford, England, U.K.) with foamtipped insert earphones (Auditory System; E-A-R, Indianapolis, IN, USA). Cerumen was not removed before assessment. Participants who failed to respond to a $30-\mathrm{dB}$ screening tone in either ear at a frequency of $0.5,1,2,4$, or $8 \mathrm{kHz}$ were considered to have failed screening and proceeded to full audiometric testing to establish air-conduction thresholds at $0.5,1,2,4$, and $8 \mathrm{kHz}$ bilaterally. Masking was used for threshold differences greater than $70 \mathrm{~dB}$. Hearing loss was defined by WHO criteria of pure-tone average (PTA) greater than $25 \mathrm{~dB}(0.5,1,2,4 \mathrm{kHz})$ (26) and designated as unilateral or bilateral in mutually exclusive categories. Further characterization by WHO grade of hearing impairment (mild, 26-40 dB; moderate, 41-60 dB; and severe, $61-80 \mathrm{~dB}$ ) was performed. Because of insufficient numbers in individual severity categories, analyses maintained stratification of subjects as having normal hearing or any unilateral or bilateral hearing loss.

Nonverbal intelligence was assessed by administering the Test of Nonverbal Intelligence, 3rd Edition (TONI-3) (27) to a systematic sample of ear health and hearing survey participants, chosen using a random start with selection of every fifth subject. TONI-3 is a language-free evaluation of intelligence that resembles a matrix analogy test, with five training figures and 45 test figures of progressively increasing difficulty, each with four to six possible responses. During a period of 2 weeks before initiation of testing, two female Nepali interviewers were trained by the Johns Hopkins project coordinator (J. S.) and a Nepali senior field staff member to administer the TONI examination according to instruction manual procedures (27). Supervised practice interviews were conducted with a convenience sample of volunteer young adults who were not part of the study. The two trained interviewers administered the test using a combination of verbal and pantomimed instructions, and the subjects indicated their responses by pointing. All subjects began with Figure 1 of the test and continued until the last figure was 
reached or a ceiling was obtained, represented by the third figure of five answered incorrectly. The three incorrect answers comprising a ceiling were not required to be consecutive (27).

\section{Outcome}

The primary outcome was nonverbal intelligence. Raw TONI-3 scores were standardized based on a normative U.S. sample of children and adults $(\mathrm{n}=3,451)$ according to manual guidelines. This study represents the first use of TONI-3 in Nepal; thus, there is no Nepali normative sample for external comparison. All analyses were conducted using recommended standardized scores, which have a mean of 100 and standard deviation (SD) of 15 (27).

\section{Demographic Variables}

Socioeconomic and demographic data applicable in this rural South Asian culture were collected by interviewers. Literacy and grade completed were collected by self-report, with education level categorized as no education, primary (grades 1-5), secondary (grades 6-10), or upper secondary and beyond (grades 11+). There were too few subjects who had attended or completed college to designate a separate category for education beyond grade 11 . Socioeconomic status was measured by typical asset ownership, including land; items of value such as a working radio, watches, and animals; caste; and type of latrine, reflecting thresholds of household sanitation in rural society. Occupation was categorized as student, employed (labor, service, or business), farmer, or unemployed.

\section{Statistical Analysis}

The $\chi^{2}$ test was used to compare baseline socioeconomic factors across four categories of TONI-3 score: greater than or equal to the standardized mean $(\geq 100)$, between the mean and 1 SD below the mean $(<100$ to 85$), 1$ to 2 SD below the mean $(<85$ to 70$)$, and less than 2 SD below the mean $(<70)(27)$. These categories were developed based on TONI-3 manual guidelines stipulating appropriate cutoffs for poor and very poor scores (27). Boxplots were used to illustrate the range of nonverbal intelligence scores in normal-hearing participants and those with unilateral and bilateral losses. Because of nonnormality of the data, the nonparametric Wilcoxon rank-sum test was used to obtain $p$ values for these comparisons, with the null hypothesis of no between-group differences rejected at $p<0.05$.

Simple and multiple linear regressions were performed to evaluate the change in nonverbal intelligence score by socioeconomic factors and hearing status. The nonverbal intelligence outcome was non-normally distributed by quantile-quantile plot, kernel density plot, and Shapiro-Wilk statistic $(p<0.001)$ and remained non-normally distributed despite log transformation $(p<0.001)$. Bootstrapping with 2,000 iterations was therefore performed during simple and multiple linear regression analyses to account for non-normality (28). The final model was selected based on Akaike information criteria (29). Forward and backward selection produced the same final model. Wald $p$ values were reported for categoric variables. Because of our previously reported effect of vitamin A allocation reducing hearing loss attributed to otitis media (23), interaction by childhood trial allocation to vitamin A versus placebo was assessed in the linear regression model and was not found to be present.

Collinearity was assessed in the multiple linear regression model using variance inflation factors. A sensitivity analysis using multiple imputation of missing data $(n=55 / 819)$ and exclusion of outliers with high leverage and influence was performed (28).
Results from all sensitivity analyses were similar to the original analysis, so results using complete data $(\mathrm{n}=764)$ were reported. Analyses were conducted using STATA 12.1 (StataCorp, College Station, TX, USA). Two-sided values of $p<0.05$ were considered significant.

This study was jointly approved by the institutional review boards at the Institute of Medicine, Tribhuvan University, Kathmandu, Nepal, and the Johns Hopkins Bloomberg School of Public Health, Baltimore, MD, USA.

\section{RESULTS}

During the original trial, a total of 6,257 children ranging from newborn to age 60 months were recruited from 40 of 261 wards, randomly selected across quadrants of the larger study area (10 per stratum), to participate in enhanced nutritional, eye, ear, and health assessments. During the reenumeration census in 2006, 2,325 of these subjects were reportedly no longer residents of the study area and 286 had died, leaving 3,646 subjects (58\%) to participate in the ear health and hearing survey from 2006 to 2008. A preselected systematic sample of $819(22 \%)$ subjects underwent nonverbal intelligence testing, of whom 55 were excluded because of missing data (10 related to hearing, 44 for education, and one for socioeconomic status). A total of 764 subjects were used in the final analysis: 397 (52\%) from the vitamin A group and 367 (48\%) from the placebo group of the original vitamin A trial (22).

Demographic and socioeconomic factors were associated with higher nonverbal intelligence scores (Table 1). Ten percent of male subjects scored greater than the normalized mean of 100 compared with $3 \%$ of female subjects $(p<0.001)$. Twelve percent of subjects of higher caste scored in the highest category compared with $6 \%$ of subjects in others castes or sects $(p<0.001)$. Subjects who reported bicycle $(8 \% ; p<0.001)$, watch $(10 \% ; p<$ $0.001)$, or latrine ownership $(14 \% ; p<0.001)$ were more likely to score 100 or higher. Literacy, years of schooling, and occupation were strongly associated with nonverbal intelligence, with $9 \%$ of literate and $0 \%$ illiterate subjects scoring 100 or higher $(p<0.001)$. Twenty percent of subjects having completed grade 11 or greater scored 100 or higher compared with $0 \%$ with no education $(p<$ 0.001 ). By contrast, $53 \%$ of subjects reporting no education $(p<0.001)$ and $49 \%$ who were illiterate $(p<0.001)$ scored in the lowest nonverbal intelligence category of less than 70, two SDs below the standardized mean. Fourteen percent of subjects reporting their occupation as student scored 100 or higher, whereas $0 \%$ of subjects reporting being unemployed scored 100 or higher $(p<$ $0.001)$. Mean age $(p=0.72)$ and allocation to vitamin A versus placebo $(p=0.32)$ were not associated with nonverbal intelligence scores.

The prevalence of bilateral hearing loss in this cohort based on WHO criteria of PTA greater than $25 \mathrm{~dB}(0.5,1$, $2,4 \mathrm{kHz})$ was $2.75 \%(\mathrm{n}=21 / 764 ; 95 \% \mathrm{CI}, 1.59-3.91)$. Twenty of 21 subjects with bilateral hearing loss had mild or moderate losses, and one had severe loss. The mean PTA in the better hearing ear of the bilateral hearing loss 
TABLE 1. Standardized TONI-3 scores by demographic and socioeconomic status $(N=764)$

\begin{tabular}{|c|c|c|c|c|c|}
\hline \multicolumn{6}{|c|}{ n (\%) with TONI-3 score } \\
\hline Characteristic & $\geq 100, \mathrm{n}=54(7 \%)$ & 99 to $85, \mathrm{n}=133(17 \%)$ & 84 to $70, \mathrm{n}=449(58 \%)$ & $<70, \mathrm{n}=128(17 \%)$ & $p$ value $^{a}$ \\
\hline Sex & & & & & $<0.001$ \\
\hline Male & $45(10)$ & $102(23)$ & $250(55)$ & $55(12)$ & \\
\hline Female & $9(3)$ & $31(10)$ & 199 (64) & $73(23)$ & \\
\hline Mean age (SD) (yr) & $18(2)$ & $19(2)$ & $19(2)$ & $19(2)$ & 0.72 \\
\hline Caste & & & & & $<0.001$ \\
\hline Higher $^{b}$ & $20(12)$ & $60(35)$ & $87(50)$ & $6(3)$ & \\
\hline Lower & $34(6)$ & $73(12)$ & $362(61)$ & $122(21)$ & \\
\hline Literacy & & & & & $<0.001$ \\
\hline Literate & $54(9)$ & $132(23)$ & $357(61)$ & $40(7)$ & \\
\hline Illiterate & $0(0)$ & $1(1)$ & $92(51)$ & $88(49)$ & \\
\hline Education & & & & & $<0.001$ \\
\hline None & $0(0)$ & $1(1)$ & $78(46)$ & $89(53)$ & \\
\hline Grades $1-5$ & $0(0)$ & $6(5)$ & $95(81)$ & $16(14)$ & \\
\hline Grades $6-10$ & $32(9)$ & $77(21)$ & $241(65)$ & $21(6)$ & \\
\hline$\geq$ Grade 11 & $22(20)$ & $49(45)$ & $35(32)$ & $2(2)$ & \\
\hline Occupation & & & & & $<0.001$ \\
\hline Student & $50(14)$ & $111(30)$ & $191(52)$ & $15(4)$ & \\
\hline Employed $^{c}$ & $1(1)$ & $13(8)$ & $100(62)$ & $48(30)$ & \\
\hline Farmer & $3(2)$ & $8(5)$ & $110(71)$ & $35(22)$ & \\
\hline Unemployed & $0(0)$ & $1(1)$ & $48(61)$ & $30(38)$ & \\
\hline \multicolumn{6}{|l|}{ Ownership } \\
\hline Bicycle & $45(8)$ & $118(22)$ & $306(57)$ & $64(12)$ & $<0.001$ \\
\hline Watch & $46(10)$ & $93(20)$ & $274(58)$ & $61(13)$ & $<0.001$ \\
\hline Latrine & $35(14)$ & $76(31)$ & $124(50)$ & $11(4)$ & $<0.001$ \\
\hline Original trial allocation & & & & & 0.32 \\
\hline Vitamin A & $26(7)$ & $63(16)$ & $246(62)$ & $62(16)$ & \\
\hline Placebo & $28(8)$ & $70(19)$ & $203(55)$ & $66(18)$ & \\
\hline
\end{tabular}

${ }^{a}$ All $p$ values by $\chi^{2}$ test except for age (one-way analysis of variance).

${ }^{b}$ Brahmin or Chhetri versus others.

${ }^{c}$ Laborer, service, or business.

TONI-3 indicates Test of Nonverbal Intelligence, 3rd Edition; SD, standard deviation.

group was $36.85 \mathrm{~dB}(95 \% \mathrm{CI}, 30.95-42.74)$. The prevalence of unilateral loss was $6.15 \%(\mathrm{n}=47 / 764 ; 95 \% \mathrm{CI}$, 4.44-7.86). Forty-six subjects with unilateral loss had mild or moderate losses, and one had severe loss. The mean PTA of the unilateral group was $39.07 \mathrm{~dB}$ (95\% CI, 36.28-41.85). A sensitivity analysis was performed to confirm that the two subjects with severe loss in the bilateral and unilateral hearing loss groups did not affect the results. All remaining results are reported for normal hearing and unilateral and bilateral hearing loss categories.

Figure 1 illustrates the range of nonverbal intelligence scores for normal hearing, unilateral hearing loss, and bilateral hearing loss. Nonverbal intelligence scores differed between participants with normal hearing and those with bilateral $(p=0.04)$ but not unilateral $(p=0.74)$ hearing loss.

Simple and multiple linear regressions evaluating differences in nonverbal intelligence score by hearing status and socioeconomic factors are listed in Table 2. Subjects with bilateral hearing loss scored an average of 3.16 points lower $(95 \% \mathrm{CI},-5.56$ to $-0.75 ; p=0.01)$ than subjects with normal hearing. Unilateral hearing loss $(0.97 ; 95 \%$ CI, -1.67 to $3.61 ; p=0.47$ ) was not associated with changes in nonverbal intelligence.

Male sex, education level, occupation, and latrine ownership were highly associated with nonverbal intelligence. Males scored an average of 5.38 points higher than females (95\% CI, 3.98 to $6.78 ; p<0.001)$. TONI-3 scores were associated with education in a dose-response manner, with subjects having completed grades 1 to 5, grades 6 to 10, or grade 11 and higher achieving scores that were, on average, 2.76 (95\% CI, 1.49-4.03), 6.12 (95\% CI, 4.56-7.69), and 11.87 (95\% CI, 8.60-15.14) points higher, respectively, than subjects with no education $(p<0.001)$. Subjects who reported being employed in a nonfarming occupation (labor, service, or business), working as a farmer, or being unemployed each scored, on average, $4.76(95 \% \mathrm{CI},-6.85$ to -2.67$), 4.05$ (95\% CI, -6.14 to -1.95$)$, and $3.79(95 \% \mathrm{CI},-5.77$ to -1.80$)$ points lower, respectively, than subjects who reported their occupation as student $(p<0.001)$. Subjects with latrine ownership scored an average of 3.54 points higher $(95 \%$ CI, 1.83-5.26; $p<0.001)$ than subjects with no latrine. Age was associated with a small decrease in nonverbal intelligence score $(-0.42 ; 95 \% \mathrm{CI},-0.73$ to $-0.11 ; p=0.008)$.

\section{DISCUSSION}

We hypothesized that hearing loss in adolescents and young adults in rural Nepal would be associated with decreased nonverbal intelligence. Bilateral but not unilateral hearing loss was associated with lower nonverbal intelligence scores in our study. This investigation represents the first assessment of the relationship between hearing loss and nonverbal intelligence in a low-resource 


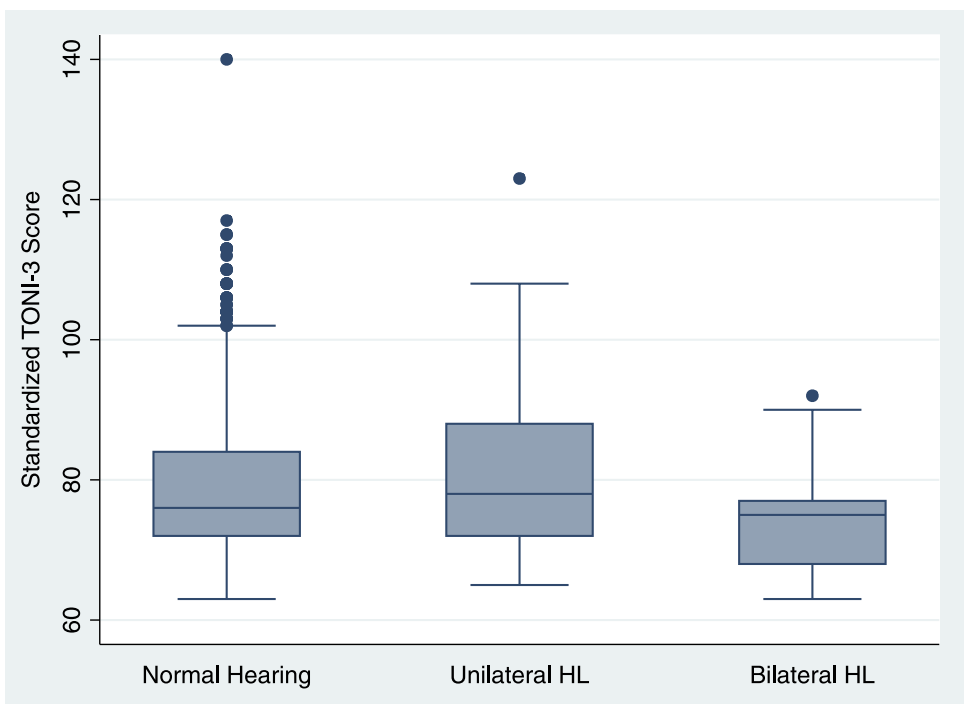

FIG. 1. Standardized nonverbal intelligence scores (TONI-3) by hearing status. TONI-3 scores differed between normal-hearing participants and those with bilateral $(p=0.04)$ but not unilateral $(p=0.74)$ hearing loss $(\mathrm{HL})$. Hearing loss was defined by WHO criteria of PTA greater than $25 \mathrm{~dB}(0.5,1,2,4 \mathrm{kHz})$.

setting of South Asia where primary ear and hearing care are not yet widely available.

The same pattern of association between nonverbal intelligence and bilateral but not unilateral hearing loss was observed in U.S. children in the National Health and Nutrition Examination Survey III (30). Teasdale and Sorensen (14) also observed lower overall IQ and lower mean scores on a nonverbal geometric figure test in subjects with mild bilateral hearing loss compared with normal-hearing participants in their cohort of 22,000 Danish 18-year-old men. Unilateral loss was not evaluated in this study, however. Other available evidence on the relationship between hearing loss and nonverbal intelligence is focused on severe to profound losses or cochlear implant users (15-19), decreasing its relevance to our Nepali study population. Direct comparison of our results with those of the Emmett and Francis U.S. study or Teasdale and Sorensen in the Netherlands is not appropriate because each investigation used different instruments to assess nonverbal intelligence.

One possible explanation for the differing relationship between nonverbal intelligence and bilateral versus unilateral hearing loss is that children with bilateral hearing loss are missing critical auditory input to both ears, whereas children with unilateral hearing loss have one ear that is capable of processing auditory input normally. Thus, individuals with bilateral hearing loss, even at mild levels, may have missed enough auditory input during

TABLE 2. Multiple linear regression analysis of change in TONI-3 nonverbal intelligence score by socioeconomic factors and hearing status

\begin{tabular}{|c|c|c|c|c|c|c|c|}
\hline \multicolumn{4}{|l|}{ Crude } & \multicolumn{4}{|c|}{ Adjusted $^{a}$} \\
\hline Test group & Referent & $\beta$ & $95 \% \mathrm{CI}$ & $p$ value & $\beta$ & $95 \% \mathrm{CI}$ & $p$ value \\
\hline \multicolumn{8}{|l|}{ Hearing status ${ }^{b}$} \\
\hline Unilateral HL & Normal hearing & 1.36 & $(-2.07$ to 4.79$)$ & 0.44 & 0.97 & $(-1.67$ to 3.61$)$ & 0.47 \\
\hline Bilateral HL & Normal hearing & -4.75 & $(-8.16$ to -1.34$)$ & 0.006 & -3.16 & $(-5.56$ to -0.75$)$ & 0.01 \\
\hline Male & Female & 6.39 & $(4.95-7.83)$ & $<0.001$ & 5.38 & $(3.98-6.78)$ & $<0.001$ \\
\hline Age & Age +1 yr & -0.28 & $(-0.62$ to 0.06$)$ & 0.11 & -0.42 & $(-0.73$ to -0.11$)$ & 0.008 \\
\hline Education & & & & $<0.001$ & & & $<0.001$ \\
\hline Grades $1-5$ & None & 4.93 & $(3.76-6.11)$ & & 2.76 & $(1.49-4.03)$ & \\
\hline Grades $6-10$ & None & 11.66 & $(10.39-12.94)$ & & 6.12 & $(4.56-7.69)$ & \\
\hline$\geq$ Grade 11 & None & 19.64 & $(17.51-21.78)$ & & 11.87 & $(8.60-15.14)$ & \\
\hline Occupation & & & & $<0.001$ & & & $<0.001$ \\
\hline Employed & Student & -10.39 & $(-12.05$ to -8.73$)$ & & -4.76 & $(-6.85$ to -2.67$)$ & \\
\hline Farmer & Student & -10.00 & $(-11.68$ to -8.31$)$ & & -4.05 & $(-6.14$ to -1.95$)$ & \\
\hline Unemployed & Student & -13.28 & $(-15.05$ to -11.52$)$ & & -3.79 & $(-5.77$ to -1.80$)$ & \\
\hline Ownership & & & & & & & \\
\hline Latrine & None & 9.06 & $(7.32-10.79)$ & $<0.001$ & 3.54 & $(1.83-5.26)$ & $<0.001$ \\
\hline
\end{tabular}

${ }^{a}$ Adjusted for the other variables in the table. Multiple linear regression $\mathrm{B}_{0}=79.83$ (95\% CI, 74.54-85.12).

${ }^{b}$ PTA greater than $25 \mathrm{~dB}(0.5,1,2$, and $4 \mathrm{kHz})$.

TONI-3 indicates Test of Nonverbal Intelligence, 3rd Edition; PTA, pure-tone average; 95\% CI, 95\% confidence interval; HL, hearing loss. 
childhood that they failed to develop to the same intellectual potential as their normal-hearing peers. In a landmark study on parent-child interaction, Hart and Risley (31) observed that children's academic success and IQ were directly correlated to the amount parents spoke to their children, suggesting that auditory stimulation is critical to childhood intellectual development. Although Hart and Risley focused on linguistic development, it is possible that auditory stimulation works through similar mechanisms to promote maturation of nonverbal intellect as well.

Several socioeconomic factors were strongly associated with nonverbal intelligence in our study, including education, occupation, and asset ownership. Risk of hearing loss has also been associated with a lower socioeconomic status $(7,32)$, raising the question of whether socioeconomic status mediates the relationship between hearing loss and nonverbal intelligence. In our study, this does not appear to be the case, as the magnitude and significance of the relationship between hearing loss and nonverbal intelligence did not change substantially after controlling for important socioeconomic factors.

There is much debate in the psychology literature regarding bias and cultural loading in cognitive tests (33). Although nonverbal assessments such as TONI-3 are believed to have inherently less cultural loading than tests involving language (27), we cannot rule out the effect of cultural differences. Indeed, greater than $90 \%$ of TONI-3 scores fell below the standardized mean in this Nepali cohort. Raw scores are standardized using normalized standards developed from U.S. children and adults (27), and thus it is highly likely that at least some degree of cultural loading and/or bias contributed to the observed downward shift in scores. This study represents the first use of TONI in Nepal, and thus a Nepali normative sample for comparison does not exist. We therefore focused on relative differences in scores between normal-hearing participants and those with hearing loss instead of drawing inference from absolute scores. Future studies using TONI in Nepal are needed, especially the development of a local reference cohort for score normalization.

There are limitations to our study that should be addressed when designing research in this area. The prevalence of hearing loss in our study was comparable to the previous estimate from Nepal (20) of $8.3 \%$, but as a result of our relatively small sample size of less than 800 , we had only 21 subjects with bilateral loss. This meant that we were unable to analyze the data by hearing loss severity and instead were required to rely on overall categories of unilateral and bilateral hearing loss. All but two affected individuals had mild to moderate hearing loss; however, so even with the broad categories dictated by our sample size, severity was relatively homogeneous. Because our audiometric testing included only air conduction, we were unable to discriminate between sensorineural and conductive losses. It would be beneficial to include bone conduction in future studies to further explore whether the type of loss modifies the observed relationship with nonverbal intelligence. Intelligence tests such as TONI-3 are traditionally administered by psychologists, and studies involving participants with hearing loss have personnel with a background working with the hearing impaired. In the lowresource setting of rural southern Nepal, no psychologists were readily available for test administration. Thus, we had to rely on training two experienced Nepali interviewers to administer the test according to manual guidelines. Lastly, detailed information on age at diagnosis is not available in this study and therefore could not be accounted for in the analysis. In a setting where primary ear and hearing care is not readily available, there were no study participants who used amplification or had participated in speech therapy.

Our study provides an important addition to the literature on nonverbal intelligence and hearing loss. The adverse effect of bilateral hearing loss on nonverbal intelligence in Nepal may represent one of the pathways through which hearing impairment leads to negative economic outcomes. The observed association with decreased nonverbal intelligence provides strong support for expanding primary ear and hearing care in rural lowresource settings in South Asia. Future research is necessary to determine whether early childhood interventions to reduce the prevalence and impact of hearing loss will be effective in ameliorating this negative association. Particularly in settings such as Nepal, where chronic suppurative otitis media is highly prevalent $(20,21,34)$, interventions that include not only early identification but also improved infection management will likely be vital. Whether through intelligence, education, or an entirely distinct pathway, improved understanding of the mechanisms behind poor economic outcomes in hearing loss is an emerging public health priority in South Asia.

Acknowledgments: The authors thank Parul Christian, Christine Stewart, Luke Mullany, Sharada Ram Shrestha (deceased), James Tielsch, Joanne Katz, Darrell Mast, Andre Hackman, and Tirta Raj Sakya; field and data management staff of the study team; and hearing technicians Jaisi Lal (deceased) and Matrika Dungel.

\section{REFERENCES}

1. World Health Organization. Deafness and hearing loss, 2014. Available at: http://www.who.int/mediacentre/factsheets/fs300/en/. Accessed March 1, 2014.

2. Järvelin MR, Mäki-Torkko E, Sorri MJ, et al. Effect of hearing impairment on educational outcomes and employment up to the age of 25 years in northern Finland. Br J Audiol 1997;31:165-75.

3. Hasson D, Theorell T, Westerlund H, et al. Prevalence and characteristics of hearing problems in a working and non-working Swedish population. J Epidemiol Community Health 2010;64:453-60.

4. Hogan A, O’Loughlin K, Davis A, et al. Hearing loss and paid employment: Australian population survey findings. Int $J$ Audiol 2009;48:117-22.

5. Jung D, Bhattacharyya N. Association of hearing loss with decreased employment and income among adults in the United States. Ann Otol Rhinol Laryngol 2012;121(12):771-5.

6. Ruben RJ. Redefining the survival of the fittest: communication disorders in the 21st century. Laryngoscope 2000;110(2 Pt 1):241-5.

7. Emmett SD, Francis HF. The socioeconomic impact of hearing loss in US adults. Otol Neurotol 2014 Aug 25 (Epub ahead of print). doi: 10.1097/MAO.0000000000000562.

8. Zagorsky JL. Do you have to be smart to be rich? The impact of IQ on wealth, income and financial distress. Intelligence 2007;35:489-501. 
9. Bess FH, Dodd-Murphy J, Parker RA. Children with minimal sensorineural hearing loss: prevalence, educational performance, and functional status. Ear Hear 1998;19:339-54.

10. Khairi Md Daud M, Noor RM, Rahman NA, Sidek DS, Mohamad A The effect of mild hearing loss on academic performance in primary school children. Int J Pediatr Otorhinolaryngol 2010;74:67-70.

11. Lieu JEC, Tye-Murray N, Fu Q. Longitudinal study of children with unilateral hearing loss. Laryngoscope 2012;122:2088-95.

12. Neisser U, Boodoo G, Bouchard TJ Jr, et al. Intelligence: knowns and unknowns. Am Psychol 1996;51:77-101.

13. Davis A, Hind S. The impact of hearing impairment: a global health problem. Int J Pediatr Otorhinolaryngol 1999;49:S51-4.

14. Teasdale TW, Sorensen MH. Hearing loss in relation to educational attainment and cognitive abilities: a population study. Int $J$ Audiol 2007;46:172-5.

15. Khan S, Edwards L, Langdon D. The cognition and behaviour of children with cochlear implants, children with hearing aids and their hearing peers: a comparison. Audiol Neurootol 2005;10: $117-26$.

16. Zekveld AA, Deijen JB, Goverts ST, et al. The relationship between nonverbal cognitive functions and hearing loss. J Speech Lang Hear Res 2007;50:74-82.

17. Edwards L, Anderson S. The association between visual, nonverbal cognitive abilities and speech, phonological processing, vocabulary and reading outcomes in children with cochlear implants. Ear Hear, 2014;35:366-74.

18. Caudle SE, Katzenstein JM, Oghalai JS, et al. Nonverbal cognitive development in children with cochlear implants: relationship between the Mullen Scales of Early Learning and later performance on the Leiter International Performance Scales-Revised. Assessment 2014;21:119-28.

19. Krivitski EC. Profile analysis of deaf children using the Universal Nonverbal Intelligence Test. J Psychoeduc Assess 2004;22: 338-50.

20. Little P, Bridges A, Guragain R, et al. Hearing impairment and ear pathology in Nepal. J Laryngol Otol 1993;107:395-400.

21. Schmitz J, Pillion JP, Leclerq SC, et al. Prevalence of hearing loss and ear morbidity among adolescents and young adults in rural southern Nepal. Int J Audiol 2010;49:388-94.
22. West KP, Pokhrel RP, Katz J, et al. Efficacy of vitamin A in reducing preschool child mortality in Nepal. Lancet 1991;338:67-71.

23. Schmitz J, West KP, Khatry SK, et al. Vitamin A supplementation in preschool children and risk of hearing loss as adolescents and young adults in rural Nepal: randomised trial cohort follow-up study. BMJ 2012;344:d7962.

24. Khatry SK, West KP Jr, Katz J, et al. Epidemiology of xerophthalmia in Nepal: a pattern of household poverty, childhood illness, and mortality. Arch Ophthalmol 1995;113:425-29.

25. West KP, Katz J, Shrestha SR, et al. Mortality of infants $<6$ mo of age supplemented with vitamin A: a randomized, double-masked trial in Nepal. Am J Clin Nutr 1995;62:143-8.

26. World Health Organization. Grades of hearing impairment. Available at: http://www.who.int/pbd/deafness/hearing_impairment_grades/en/ index.html. Accessed March 1, 2014.

27. Brown L, Johnsen SK, Sherbenou RJ. Test of Nonverbal Intelligence, 3rd Edition Examiner's Manual, ProEd: Austin, TX, 1997.

28. StataCorp. Stata 12 Base Reference Manual. College Station, TX: Stata Press, 2011.

29. Burnham KP, Anderson DR. Information and likelihood theory: a basis for model selection and inference. In: Burnham KP, Anderson DR, eds. Model Selection and Multimodel Inference: A Practical Information-Theoretic Approach, 2nd ed, Fort Collins, CO: Springer, 2002:49-97.

30. Emmett SD, Francis HF. Bilateral hearing loss is associated with decreased nonverbal intelligence in US children aged 6 to 16 years. Laryngoscope 2014;124:2176-81.

31. Hart B, Risley TR. Meaningful Differences in the Everyday Experience of Young American Children. Baltimore, MD: Paul H Brookes Publishing, 1995.

32. Olusanya BO, Ruben RJ, Parving A. Reducing the burden of communication disorders in the developing world: an opportunity for the millennium development project. JAMA 2006;296:441-4.

33. Reynolds CR, Suzuki LA. Bias in psychological assessment: an empirical review and recommendations. Handbook of Psychology, 2nd ed. Hoboken, NJ: John Wiley \& Sons, Inc; 2012:82-113.

34. Adhikari P. Pattern of ear diseases in rural school children: experiences of free health camps in Nepal. Int J Pediatr Otorhinolaryngol 2009;73:1278-80. 